\title{
Reversals of Age-Related Declines in Neuronal Signal Transduction, Cognitive, and Motor Behavioral Deficits with Blueberry, Spinach, or Strawberry Dietary Supplementation
}

\author{
James A. Joseph, ${ }^{1}$ Barbara Shukitt-Hale, ${ }^{1}$ Natalia A. Denisova, ${ }^{1}$ Donna Bielinski, ${ }^{1}$ Antonio Martin, ${ }^{1}$ \\ John J. McEwen, ${ }^{1}$ and Paula C. Bickford ${ }^{2}$ \\ 1 United States Department of Agriculture, Human Nutrition Research Center on Aging, Tufts University, Boston, \\ Massachusetts 02111, and 2Department of Veterans Affairs Medical Center, Denver, Colorado 80262
}

Ample research indicates that age-related neuronal-behavioral decrements are the result of oxidative stress that may be ameliorated by antioxidants. Our previous study had shown that rats given dietary supplements of fruit and vegetable extracts with high antioxidant activity for 8 months beginning at 6 months of age retarded age-related declines in neuronal and cognitive function. The present study showed that such supplements (strawberry, spinach, or blueberry at 14.8, 9.1, or 18.6 gm of dried aqueous extract per kilogram of diet, respectively) fed for 8 weeks to 19-month-old Fischer 344 rats were also effective in reversing age-related deficits in several neuronal and behavioral parameters including: oxotremorine enhancement of $\mathrm{K}^{+}$-evoked release of dopamine from striatal slices, carbachol-stimulated GTPase activity, striatal $\mathrm{Ca}^{45}$ buffering in striatal synaptosomes, motor behavioral performance on the rod walking and accelerod tasks, and Morris water maze performance. These findings suggest that, in addition to their known beneficial effects on cancer and heart disease, phytochemicals present in antioxidant-rich foods may be beneficial in reversing the course of neuronal and behavioral aging.

Key words: phytonutrients; aging; dopamine; striatum; cognitive behavior; motor behavior
It is well known that there are a number of neuronal and behavioral changes that take place as a function of aging, even in the absence of neurodegenerative diseases. These changes may include decrements in calcium homeostasis (Landfield and Eldridge, 1994) and in the sensitivity of several receptor systems, most notably: (1) adrenergic (Gould and Bickford, 1997); (2) dopaminergic (Joseph et al., 1978; Levine and Cepeda, 1998); (3) muscarinic (Joseph et al., 1990; Yufu et al., 1994; Egashira et al., 1996); and (4) opioid (Kornhuber et al., 1996; Nagahara et al., 1996). These decrements can be expressed, ultimately, as alterations in both motor (Joseph et al., 1983; Kluger et al., 1997) and cognitive behaviors (Bartus, 1990).

Although the major factors involved in these age-related declines remain to be specified, a great deal of research in recent years has suggested that one of the most important may be reductions in the ability to mitigate the long-term effects of oxidative stress (OS). This appears to be particularly evident in Parkinson's disease (PD) (Jenner, 1996) and Alzheimer's disease (AD) (Finch and Cohen, 1997). In AD, for example, several studies have shown increased: (1) OS and damage to proteins tau and neurofilaments (Smith et al., 1995); (2) A $\beta$-mediated OSinduced cell death (Smith et al., 1996; Pike et al., 1997; Daniels et al., 1998); and (3) protein carbonyls (Smith et al., 1991) and 4-hydroxynonenal (Sayre et al., 1997).

If $\mathrm{OS}$ is indeed a major factor in brain aging and in age-related neurodegenerative disease, it would seem that some of its deleterious effects could be retarded or even reversed by increasing

\footnotetext{
Received April 16, 1999; revised June 18, 1999; accepted July 1, 1999.

This work was supported by the United States Department of Agriculture.

Correspondence should be addressed to Dr. J. A. Joseph, United States Department of Agriculture, Human Nutrition Research Center on Aging, Tufts University, Room 919, 711 Washington Street, Boston, MA 02111.

Copyright (C) 1999 Society for Neuroscience 0270-6474/99/198114-08\$05.00/0
}

antioxidant levels, and that the putative synergistic effects of combinations of antioxidants might be particularly effective in this regard. Our findings have suggested that this might be accomplished by increasing the dietary intake of fruits and vegetables.

In a previous study we examined whether long-term (from 6-15 months of age; F344 rats) feeding with a control diet (AIN-93) or a diet supplemented with a strawberry or spinach extract that had been identified as being high in antioxidant activity via the oxygen radical absorbance capacity assay (ORAC; Cao et al., 1995, 1996; Wang et al., 1996) or vitamin E would forstall the effects of aging. Results indicated that the supplemented diets could prevent the onset of age-related deficits in several indices [e.g., signal transduction, such as oxotremorine-enhanced striatal dopamine release (ox-K ${ }^{+}$-ERDA)], as well as cognitive behavior (e.g., Morris water maze performance), with spinach having the greatest effects (Joseph et al., 1998). These results suggested that phytochemicals present in antioxidant-rich foods could be beneficial in forestalling functional age-related deficits.

However, although these results are interesting, it is important to note that at present, the world population comprised of people over 65 years of age represents $>50 \%$ of all those who have ever lived to attain this age. Therefore, it is important to determine whether these dietary supplementations might be effective in aged organisms. Thus, the purpose of the present experiment was to examine whether dietary supplementations (for 8 weeks) with spinach, strawberry, or blueberry (Prior et al., 1998) extracts in an AIN-93 diet would be effective in reversing age-related deficits in neuronal and behavioral function in aged (19 months) Fischer 344 rats.

\section{MATERIALS AND METHODS}

Note that for these experiments we employed age-valid tests in which Fischer 344 rats had been shown to exhibit decrements by 15 months of age (Joseph et al., 1998; Shukitt-Hale et al., 1998b). 
Table 1. Diets fed to rats (for 8 weeks, from age 19-21 months)

Diet composition $(\mathrm{gm} / \mathrm{kg})$

\begin{tabular}{|c|c|c|c|c|}
\hline \multirow{2}{*}{ Ingredient } & \\
\hline & Control & + Strawberry & + Spinach & + Blueberry \\
\hline Casein, alcohol-extracted & 189.6 & 189.6 & 189.6 & 189.6 \\
\hline L-cystine & 2.8 & 2.8 & 2.8 & 2.8 \\
\hline Corn starch & 450.2 & 435.4 & 441.1 & 431.6 \\
\hline Maltodextrin 10 & 118.5 & 118.5 & 118.5 & 118.5 \\
\hline Sucrose & 94.8 & 94.8 & 94.8 & 94.8 \\
\hline Cellulose, BW200 & 47.4 & 47.4 & 47.4 & 47.4 \\
\hline Soybean oil & 42.7 & 42.7 & 42.7 & 42.7 \\
\hline Salt $\operatorname{mix}^{a}$ & 9.5 & 9.5 & 9.5 & 9.5 \\
\hline $\mathrm{CaPO}_{4}$, dibasic & 12.3 & 12.3 & 12.3 & 12.3 \\
\hline $\mathrm{CaCO}_{3}$ & 5.2 & 5.2 & 5.2 & 5.2 \\
\hline Potassium citrate & 15.6 & 15.6 & 15.6 & 15.6 \\
\hline Sodium selenite & 0.00009 & 0.00009 & 0.00009 & 0.00009 \\
\hline Vitamin mix $(\mathrm{V} 13401)^{b}$ & 9.5 & 9.5 & 9.5 & 9.5 \\
\hline Choline bitartrate & 1.9 & 1.9 & 1.9 & 1.9 \\
\hline Strawberry extract ${ }^{c}$ & & 14.8 & & \\
\hline Spinach extract ${ }^{c}$ & & & 9.1 & \\
\hline Blueberry extract ${ }^{c}$ & & & & 18.6 \\
\hline Total & 1000 & 1000 & 1000 & 1000 \\
\hline
\end{tabular}

${ }^{a}$ Salt mix contains (in gm/kg salt mix): $\mathrm{NaCl}, 259 ; \mathrm{MgO}, 41.9 ; \mathrm{MgSO}_{4} \cdot 7 \mathrm{H}_{2} 0,257.6 ; \mathrm{CrKSO}_{4} \cdot 12 \mathrm{H}_{2} \mathrm{O}, 1.925 ; \mathrm{CuCO}_{4}, 1.05$; $\mathrm{KI}, 0.035$; FeCitrate, 21.0; $\mathrm{MnCO}_{4}, 12.25 ; \mathrm{ZnCO}_{4}, 5.6$; and sucrose, 399.64.

${ }^{b}$ Vitamin mix contains (in gm/ kg vitamin mix): Vitamin A palmitate (500,000 IU/gm), 0.8; vitamin $\mathrm{D}_{3}(100,000 \mathrm{IU} / \mathrm{gm}), 1.0$; menadione sodium bisulfate $(62.5 \%$ menadione), 0.08 ; biotin $(1.0 \%) 2.0$; cyancocobalamin $(0.1 \%), 1.0$; folic acid, 0.2 ; nicotinic acid 3.0; calcium pantothenate, 1.6; pyridoxine-HCI, 0.7; riboflavin, 0.6, thiamin-HCI, 0.6 ; and sucrose, 988.42 .

${ }^{c}$ Freeze-dried aqueous extract prepared by homogenizing, centrif uging, and then freeze drying. The freeze-dried extracts were combined with the control diet; the amount of corn starch in the control diet was adjusted accordingly when the fruit or vegetable extracts were added.

\section{Animals}

The subjects were 40 male Fischer 344 rats (Harlan Sprague Dawley, Indianapolis, IN). They were individually housed in stainless steel mesh suspended cages, provided food and water ad libitum, and maintained on a $12 \mathrm{hr}$ light/dark cycle. All rats were observed daily for clinical signs of disease. After a $5 \mathrm{~d}$ acclimatization period to the facility, the 19-monthold rats were weight-matched, given $5 \mathrm{~d}$ on the control (modified AIN93) diet (Table 1), and randomly assigned to one of the four diet groups [control, $1.48 \%$ strawberry, $0.91 \%$ spinach, or $1.86 \%$ blueberry $(\mathrm{w} / \mathrm{v})$; 10/diet group; Table 1]. The rats were fed these diets for 8 weeks before experimental testing at 21 months. The amounts of strawberry, spinach, or blueberry extracts added into the control diet were based on an equivalent ORAC activity so that each diet provided equivalent antioxidant activity (1.36 mmol Trolox equivalent per kilogram of diet, Joseph et al., 1998). Weights were recorded every 2 weeks, and food intakes (over a $48 \mathrm{hr}$ period) were performed twice during the study. These animals were used in compliance with all applicable laws and regulations as well as principles expressed in the National Institutes of Health, United States Public Health Service Guide for the Care and Use of Laboratory Animals. This study was approved by the Animal Care and Use Committee of our center.

\section{Diet preparation}

Four hundred grams of sample were added to water in the ratio of 2:1 for strawberries and spinach, and 1:1 for blueberries, then homogenized in a blender for $2 \mathrm{~min}$. The recovered homogenate was centrifuged at $13,000 \times g$ for $15 \mathrm{~min}$ at $4^{\circ} \mathrm{C}$. The diet was then prepared as described previously (Joseph et al., 1998). The amount of corn starch in the control diet was adjusted accordingly when the strawberry, spinach, or blueberry extracts were added (Table 1).

\section{Procedures}

Dopamine release. Oxotremorine enhancement of $\mathrm{K}^{+}$-ERDA was conducted as previously described (Joseph et al., 1988a,b; 1990; 1998). Briefly, cross cut (300 $\mu \mathrm{m}$; McIlwain tissue chopper) striatal slices were obtained from the animals maintained on the various diets. The slices were placed in small glass vials containing modified Krebs'-Ringer's solution basal release medium (BRM) that had been bubbled for $30 \mathrm{~min}$ with $95 \% \mathrm{O}_{2}$ and $5 \% \mathrm{CO}_{2}$ and which contained (in $\mathrm{mm}$ ) $\mathrm{NaHCO}_{3} 21$, glucose 3.4, $\mathrm{NaH}_{2} \mathrm{PO}_{4}$ 1.3, EGTA $1, \mathrm{MgCl}_{2} 0.93, \mathrm{NaCl} 127$, and $\mathrm{KCl} 2.5$ (low $\mathrm{KCl}$ ), $\mathrm{pH}$ 7.4. They were then placed in the perfusion chambers where they were maintained at $37^{\circ} \mathrm{C}$ and perfused with the BRM for 30 min. After this equilibration period, the medium was then switched to one containing (in mM) $\mathrm{KCl} 30, \mathrm{CaCl}_{2} \cdot 2 \mathrm{H}_{2} \mathrm{O} 1.26$ (in place of EGTA), $\mathrm{NaCl} 57$, and 0 or $500 \mu \mathrm{M}$ oxotremorine, and the enhancement of $\mathrm{K}^{+}$-ERDA was assessed. DA release was then quantitated by HPLC coupled to electrochemical detection. Data were expressed as picomoles per milligram of protein as determined by the Lowry et al. (1951) procedure.

GTPase activity. Striatal membranes were prepared, and low $\mathrm{K}_{\mathrm{M}}$ GTPase analysis was performed according to the method of Cassel and Selinger (1976) as modified by Yamagami et al. (1992). Low $K_{M}$ GTPase activity was calculated by subtracting the activity measured in the presence of $100 \mu \mathrm{M}$ unlabeled GTP from total activity. Activity was expressed in picomoles of $\gamma-\left[{ }^{32} \mathrm{P}\right]$ hydrolyzed per milligram of protein per minute. Values were expressed as means \pm SEM of the differences between basal and carbachol-stimulated low- $\mathrm{K}_{\mathrm{m}}$ GTPase activity $(\Delta \mathrm{G})$ in picomoles per milligram of protein per minute. Proteins were determined by the Lowry et al. (1951) method.

${ }^{45} \mathrm{Ca}^{2+}$ recovery. Striatal synaptosomes were isolated from the individual rats, and ${ }^{45} \mathrm{Ca}^{2+}$ uptake studies were performed as described previously (Joseph et al., 1998). Results were expressed as nanomoles of $\mathrm{Ca}^{2+}$ per milligram of protein. Percent of increase in ${ }^{45} \mathrm{Ca}^{2+}$ uptake (increase) and recovery at $30 \mathrm{sec}$ after depolarization (recovery) were calculated as described in Joseph et al. (1998).

Psychomotor testing. A battery of age-sensitive tests of psychomotor behavior (Joseph et al., 1983; Ingram et al., 1994; Shukitt-Hale et al., 1998b) was administered in a randomized order to the animals. Each test was performed once, separated by no less than a $1 \mathrm{hr}$ break between tasks. Briefly, the tests included: (1) rod walking, which measures psychomotor coordination and the integrity of the vestibular system by requiring the animal to balance on a stationary, horizontal rod; (2) wire suspension, which measures muscle strength and the prehensile reflex, an animal's ability to grasp a horizontal wire with its forepaws and to remain 
suspended; (3) plank walking, which measures balance and coordination by exposing the rats to different sizes of horizontal planks; (4) inclined screen, which measures muscle tone, strength, stamina, and balance by placing the animal on a wire mesh screen that is tilted $60^{\circ}$ to the horizontal plane of the floor; and (5) accelerating rotarod, which measures fine motor coordination, balance, and resistance to fatigue by measuring the amount of time that a rat can remain standing/walking on a rotating, slowly accelerating rod.

Cognitive testing. The working memory version of the Morris water maze (MWM), with a 10 min intertrial interval, was used to test spatial learning and memory (Morris, 1984; Brandeis et al., 1989; Shukitt-Hale et al., 1998b). Performance on the maze, including the working memory paradigm, has been shown to deteriorate with aging (Morris, 1984; Rapp et al., 1987; Brandeis et al., 1989; Van der Staay et al., 1993; Ingram et al., 1994; Shukitt-Hale et al., 1998b).

MWM testing was performed daily for 4 consecutive days, with a morning and an afternoon session, two trials each session, with a $10 \mathrm{~min}$ intertrial interval between the two trials. At the beginning of each trial, the rat was gently immersed in the water at one of four randomized start locations (located $90^{\circ}$ apart on the perimeter of the pool). Each rat was allowed $120 \mathrm{sec}$ to escape onto the platform (submerged $2 \mathrm{~cm}$ below the surface; its location was changed to a different quadrant for each session of testing); if the rat failed to escape within this time, it was guided to the platform. Once the rat reached the platform, it remained there for $15 \mathrm{sec}$ (trial 1; reference memory or acquisition trial). The rat was returned to its home cage between trials $(10 \mathrm{~min})$. Trial 2 (the working memory or retrieval trial) used the same platform location and start position as trial 1. Performance (latency to find platform in seconds, distance swam in centimeters, and swim speed in centimeters per second) on each trial was videotaped and analyzed with image tracking software (HVS Image, Hampton, UK). For a more detailed description of the maze and the paradigm used, see Shukitt-Hale et al. (1998a,b).

Analyses of oxidative stress. The effects of oxidative stress on the production of reactive oxygen species (ROS) in the brain tissue obtained from animals in the various diet groups was assessed using 2',7'dichlorofluorescin diacetate (DCFH-DA; Molecular Probes, Eugene, OR) analysis (Lebel et al., 1992; Ueda et al., 1997). For these experiments, striata were quickly removed from the brain, and pellets of membranes (synaptosomes, myelin, and mitochondria) were obtained and treated as described previously (Denisova et al., 1998). The results were expressed as a percent of control.

In addition to these analyses, total glutathione (GSH) levels were also analyzed using the procedure described in Shukitt-Hale et al. (1998a).

Vitamin E analyses. Vitamin E ( $\alpha$-tocopherol and $\gamma$-tocopherol) content of tissues was measured by reverse-phase HPLC as described in Martin et al. (1997). Briefly, $100 \mu \mathrm{l}$ of homogenized tissue was mixed with $100 \mu \mathrm{l}$ ethanol; after vortexing, tocopherols were extracted into 500 $\mu \mathrm{l}$ hexane containing $0.002 \%$ butylated hydroxyl toluene (BHT). Tocol (a gift from Hoffmann-La Roche, Neutley, NJ) was added to the mixture as an internal standard. Samples were centrifuged at $800 \mathrm{rpm}$ for $5 \mathrm{~min}$ at $4^{\circ} \mathrm{C}$, and the supernatant was collected, dried under a stream of nitrogen gas, and reconstituted in $100 \mu \mathrm{l}$ of methanol. Tocopherols were separated by HPLC using a $3 \mu \mathrm{m} \mathrm{C18} \mathrm{reverse} \mathrm{phase} \mathrm{column} \mathrm{and} \mathrm{eluted} \mathrm{peaks}$ detected with an amperometric electrochemical detector (Bioanalytical Systems, West Lafayette, IN). Peaks were integrated with a ChemStation (Hewlett Packard); $\alpha$-tocopherol and $\gamma$-tocopherol concentration was expressed in picomoles per milligram of protein. Protein was measured by the method of Lowry et al. (1951).

\section{RESULTS}

\section{Weights}

The rats gained weight from $19-21$ months $\left(F_{(9,30)}=49.95 ; p<\right.$ $0.001)$ from an average of $405.3 \pm 0.2$ precontrol diet to $459.4 \pm$ 4.1 at age 21 months. However, there were no differences in weight between the diet groups over time $(p>0.05)$ or at age 21 months $(p>0.05)$. There were also no differences in food intakes between the diet groups over the course of the study $(p>0.05)$.

\section{DA release}

As can be seen from Figure $1 A$, all striatal slices obtained from the animals in the various diet groups (six animals per group) showed significantly greater oxo-enhanced striatal $\mathrm{K}{ }^{+}$-ERDA
A
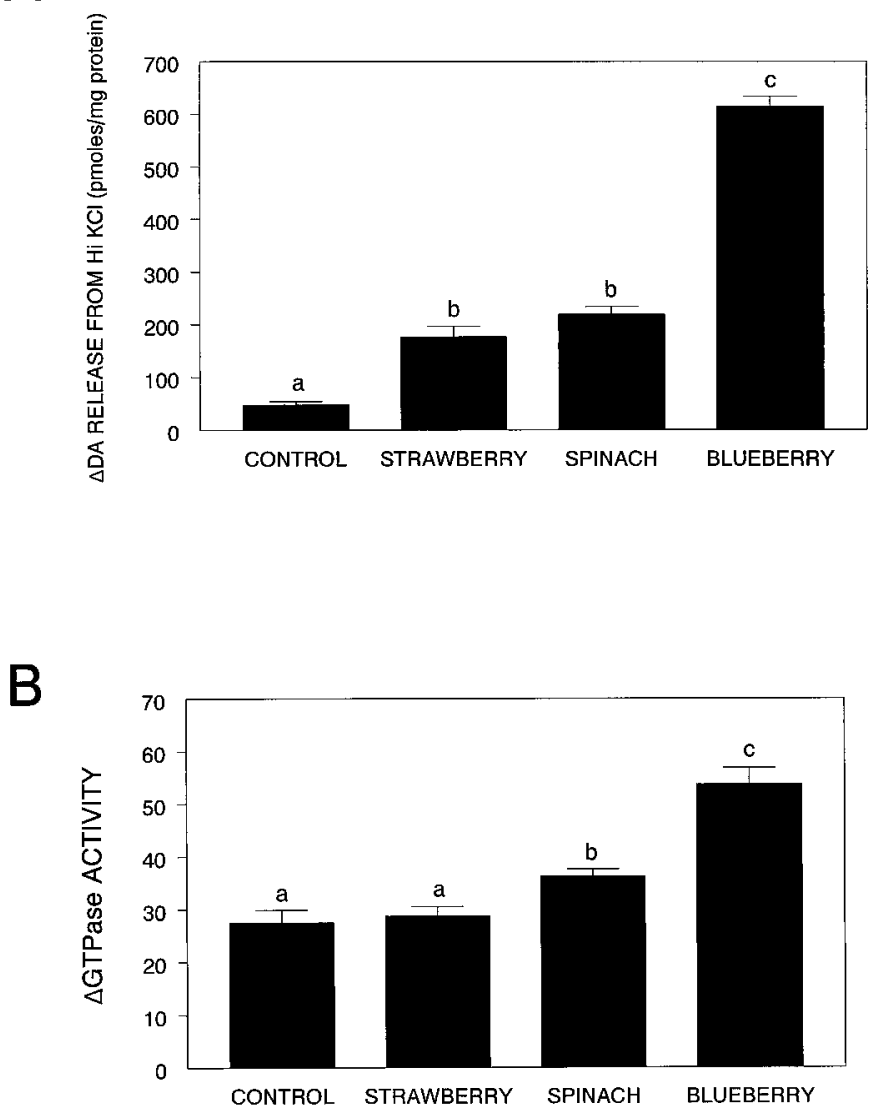

Figure 1. Oxotremorine enhancement of DA release $(A)$ and differences (expressed as change from baseline) in carbachol-stimulated low $\mathrm{K}_{\mathrm{M}}$ GTPase activity $(B)$ from striatal slices obtained and prepared from animals maintained on the control or the various antioxidant diets (mean + SEM). Means not sharing a common letter are significantly different from each other ( $p<0.05$; Fisher's LSD).

than that seen in those obtained from animals maintained on the control diet $\left(F_{(3,20)}=237.56 ; p<0.0001\right.$; Fisher's LSD test: control versus strawberry, $p<0.0001$; spinach, $p<0.0001$; blueberry, $p<0.0001]$. Additional post hoc comparisons indicated that oxo-enhanced $\mathrm{K}^{+}$-ERDA in the blueberry-fed group was greater than that seen in the strawberry-fed $(p<0.0001)$ or spinach-fed $(p<0.0001)$ groups, which were not different from each other.

\section{GTPase activity}

As Figure $1 B$ shows, there were differences between basal and carbachol-stimulated GTPase activity from striatal slices for the various diet groups (six animals per group), $\left(F_{(3,20)}=27.05 ; p<\right.$ $0.0001)$, with the spinach $(p<0.05)$ and blueberry $(p<0.0001)$ groups preventing the age-related decrement, but not the strawberry group $(p>0.05)$. Additional post hoc comparisons indicated that GTPase activity in the blueberry-fed group was greater than that seen in the strawberry-fed $(p<0.0001)$ or spinach-fed $(p<0.0001)$ groups, which were also different from each other $(p<0.05)$, with the spinach-fed group having higher activity.

\section{${ }^{45}$ Ca recovery}

As can be seen in Figure $2 A$, differences in ${ }^{45} \mathrm{Ca}^{2+}$ recovery were examined in the striatal synaptosomes obtained from the controls and various diet groups, under control and OS (exposure of the 
A

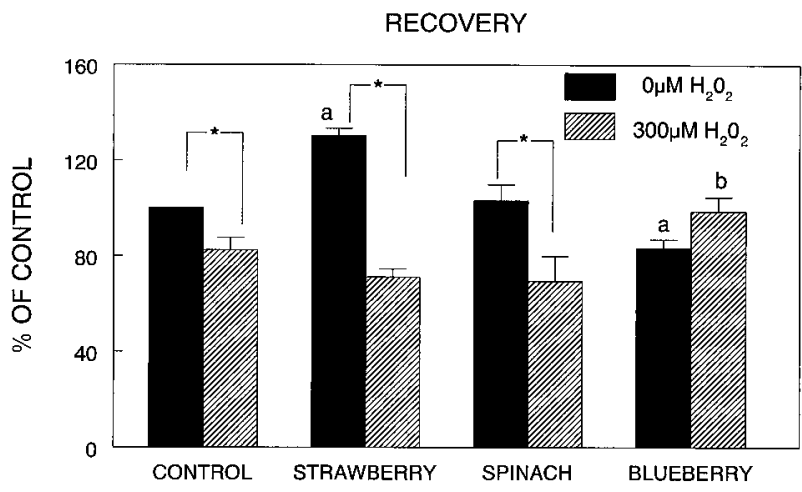

B

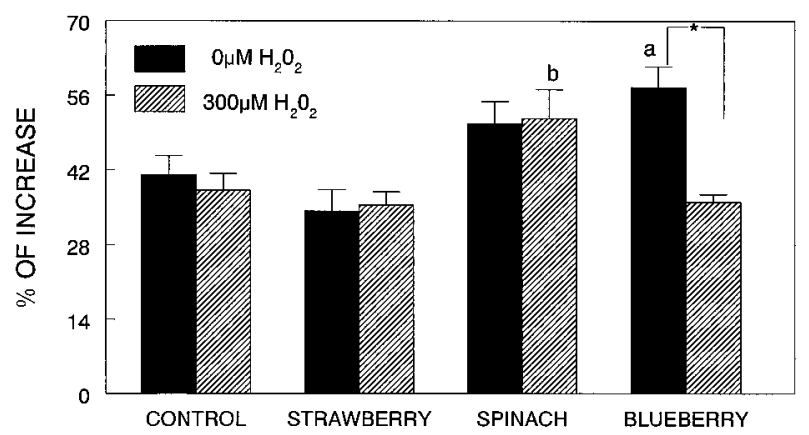

Figure 2. Calcium recovery ( $A$; expressed as percent of control) and increase in calcium ( $B$; expressed as percent increase) in synaptosomes obtained from animals in the various diet groups and exposed to 0 or 300 $\mu \mathrm{M} \mathrm{H}_{2} \mathrm{O}_{2}(15 \mathrm{~min})$ and depolarized with $60 \mathrm{mM} \mathrm{KCl}$. For this figure, $a$ differs from untreated (no $\left.\mathrm{H}_{2} \mathrm{O}_{2}\right)$ control diet group, $b$ differs from treated $\left(\mathrm{H}_{2} \mathrm{O}_{2}\right)$ control diet group, and the asterisk indicates a difference between 0 and $300 \mu \mathrm{M} \mathrm{H}_{2} \mathrm{O}_{2}$ for that diet group ( $p<0.05$; Fisher's LSD).

synaptosomes to $\mathrm{H}_{2} \mathrm{O}_{2}$ ) conditions. The results indicated that there were significant differences as a function of diet and $\mathrm{H}_{2} \mathrm{O}_{2}$ treatment $\left(F_{(3,24)}=15.49 ; p<0.0001\right)$, as well as $\mathrm{H}_{2} \mathrm{O}_{2}$ treatment alone $\left(F_{(1,24)}=35.90 ; p<0.0001\right)$. Post hoc testing showed that the strawberry diet had greater calcium recovery $(p<0.001)$, whereas the blueberry diet had lower recovery $(p<0.05)$, in non- $\mathrm{H}_{2} \mathrm{O}_{2}$-treated synaptosomes compared to the control diet. After treatment with $300 \mu \mathrm{M} \mathrm{H}_{2} \mathrm{O}_{2}$, only the blueberry group showed greater ${ }^{45} \mathrm{Ca}$ recovery $(p<0.05)$ after treatment, i.e., a greater ability to extrude or sequester calcium after depolarization, than the control group. In fact, only the blueberry-fed diet group had no deficits in ${ }^{45} \mathrm{Ca}$ recovery after exposure to $\mathrm{H}_{2} \mathrm{O}_{2}$ $(p>0.05)$, whereas ${ }^{45} \mathrm{Ca}$ recovery was significantly decreased in the $\mathrm{H}_{2} \mathrm{O}_{2}$-exposed diet control group as compared to nonexposed control $(p<0.05)$, as well as the strawberry $(p<0.0001)$ and spinach groups $(p<0.0001)$.

Calcium increase (Fig. $2 B)$ showed an effect of diet $\left(F_{(3,24)}=\right.$ 7.69; $p<0.001), \mathrm{H}_{2} \mathrm{O}_{2}\left(F_{(1,24)}=4.48 ; p<0.05\right)$, and a diet by $\mathrm{H}_{2} \mathrm{O}_{2}$ interaction $\left(F_{(3,24)}=4.24 ; p<0.05\right)$. Post hoc testing showed that striatal synaptosomes isolated from the blueberrysupplemented animals showed a greater increase in calcium in non- $\mathrm{H}_{2} \mathrm{O}_{2}$-treated synaptosomes than those from controls $(p<$ 0.01). After treatment with $300 \mu \mathrm{M} \mathrm{H}_{2} \mathrm{O}_{2}$, the spinach group had a greater increase in calcium than the control group $(p<0.05)$.
A

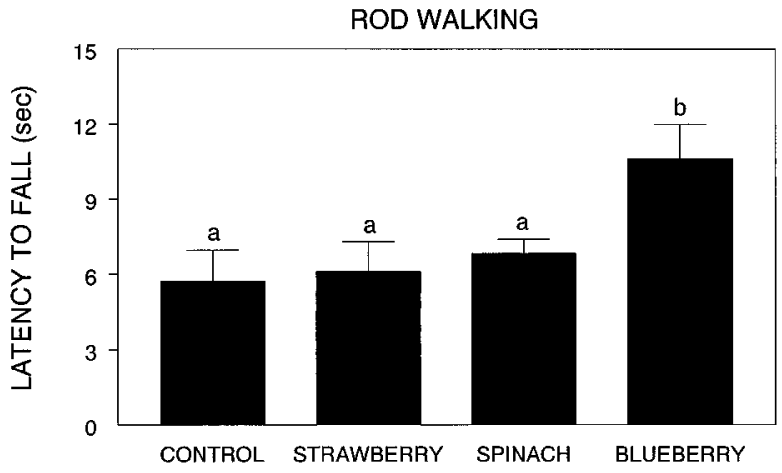

B

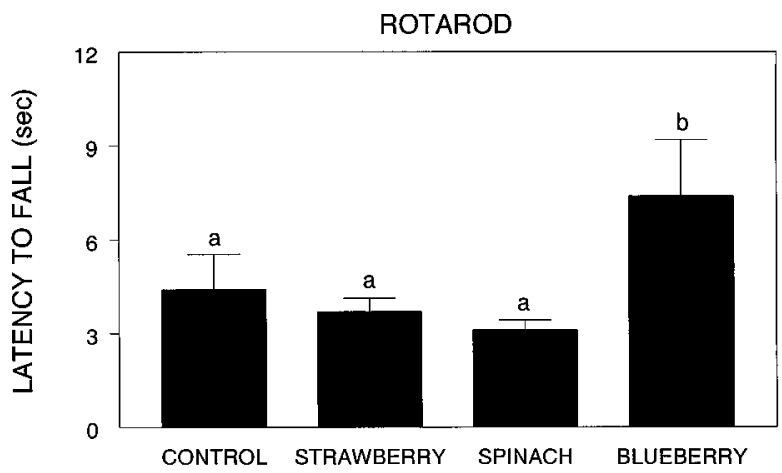

Figure 3. Performance (latency to fall, in seconds) on the rod walk $(A)$ and rotarod $(B)$ tests for the various diet groups. Means not sharing a common letter are significantly different from each other $(p<0.05$; Fisher's LSD).

However, only the blueberry diet showed a decreased calcium increase after depolarization when comparing $0 \mu \mathrm{M} \mathrm{H}_{2} \mathrm{O}_{2}$ and $300 \mu \mathrm{M} \mathrm{H} \mathrm{H}_{2} \mathrm{O}_{2}$ conditions $(p<0.0001)$.

\section{Psychomotor testing}

There were significant effects of diet on rod walking $\left(F_{(3,35)}=\right.$ $3.79 ; p<0.05)$ and the accelerating $\operatorname{rotarod}\left(F_{(3,35)}=2.89 ; p<\right.$ 0.05 ) (Fig. 3). For the rod walk, latency to fall was significantly longer in the blueberry group compared to the control $(p<0.01)$, strawberry $(p<0.01)$, and spinach groups $(p<0.05)$. Similarly, for the accelerating rotarod, latency to fall was significantly longer in the blueberry group compared to the strawberry $(p<0.05)$ and spinach $(p<0.05)$ groups, and tended to be higher than the control group $(p=0.06)$. There was no effect of diet group on wire suspension, inclined screen, or any measure of plank walking. Therefore, supplementation with the blueberry extract improved motor performance on two motor tests that rely on balance and coordination.

\section{Cognitive testing}

Although there were improvements in performance over the four testing days, as evident from significant effects of time, ANOVA showed no effects of diet for either trial 1 or trial 2 performance on latency, distance, or speed. However, when separate $t$ tests were performed between the two trial latencies for each diet (to see if the different diet groups significantly improved their per- 
A

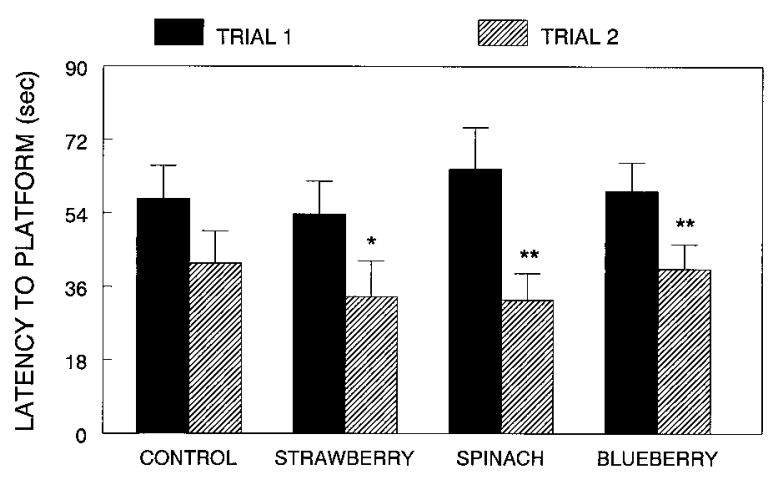

B

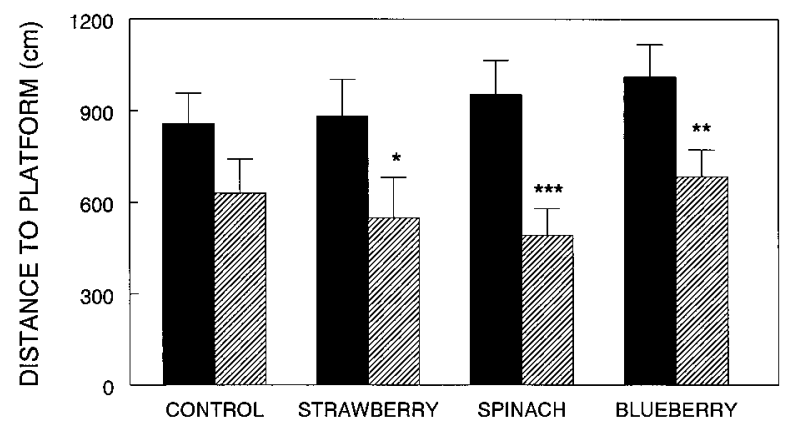

Figure 4. Morris water maze performance in the various diet groups. Performance was assessed over $4 \mathrm{~d}(2$ sessions per day, 2 trials per session). Results are given as latencies $(A)$ and distances $(B)$ to find the hidden platform for the first and second trials for each session on days 3 and 4. Asterisks indicate a difference between trial 1 and trial 2 performance for that diet group $\left({ }^{*} p<0.05 ;{ }^{*} p<0.01 ;{ }^{* *} p<0.001\right.$; Fisher's LSD).

formance from trial 1 to trial 2, as the working memory hypothesis predicts (Van der Staay and de Jonge, 1993), positive effects of diet supplementation were observed (Fig. 4). For latency to find the platform on days 3 and 4 (a time when learning the task should not interfere with the results), the strawberry $\left(t_{(9)}=2.60\right.$; $p<0.05)$, spinach $\left(t_{(8)}=5.18 ; p<0.01\right)$, and blueberry $\left(t_{(8)}=\right.$ 5.37; $p<0.01)$ groups showed significant differences between trial 1 and trial 2 , i.e., trial 2 latencies were significantly less than trial 1 , showing that these rats demonstrated one-trial learning, even with the $10 \mathrm{~min}$ retention interval. This one-trial learning was not found in the control group ( $p>0.05$ ) (Fig. 4A).

For distance swam to the platform on days 3 and 4 , similar results were found (Fig. $4 B$ ); the strawberry $\left(t_{(9)}=2.66 ; p<\right.$ $0.05)$, spinach $\left(t_{(8)}=6.85 ; p<0.001\right)$, and blueberry $\left(t_{(8)}=5.32\right.$; $p<0.01)$ groups showed significant improvements between trial 1 and trial 2, with trial 2 distances significantly less than trial 1 . Again, no significant improvement was seen from trial 1 to trial 2 in the control group $(p>0.05)$. The effects of improved working memory (trial 2) performance via diet supplementation were not caused by swim speed, because there were no differences in swim speed between trial 1 and trial 2 for any group.

\section{Oxidative stress}

As can be seen from Figure $5 A$, there were significant differences in DCF fluorescence among the various groups $\left(F_{(3,21)}=4.63\right.$;
A
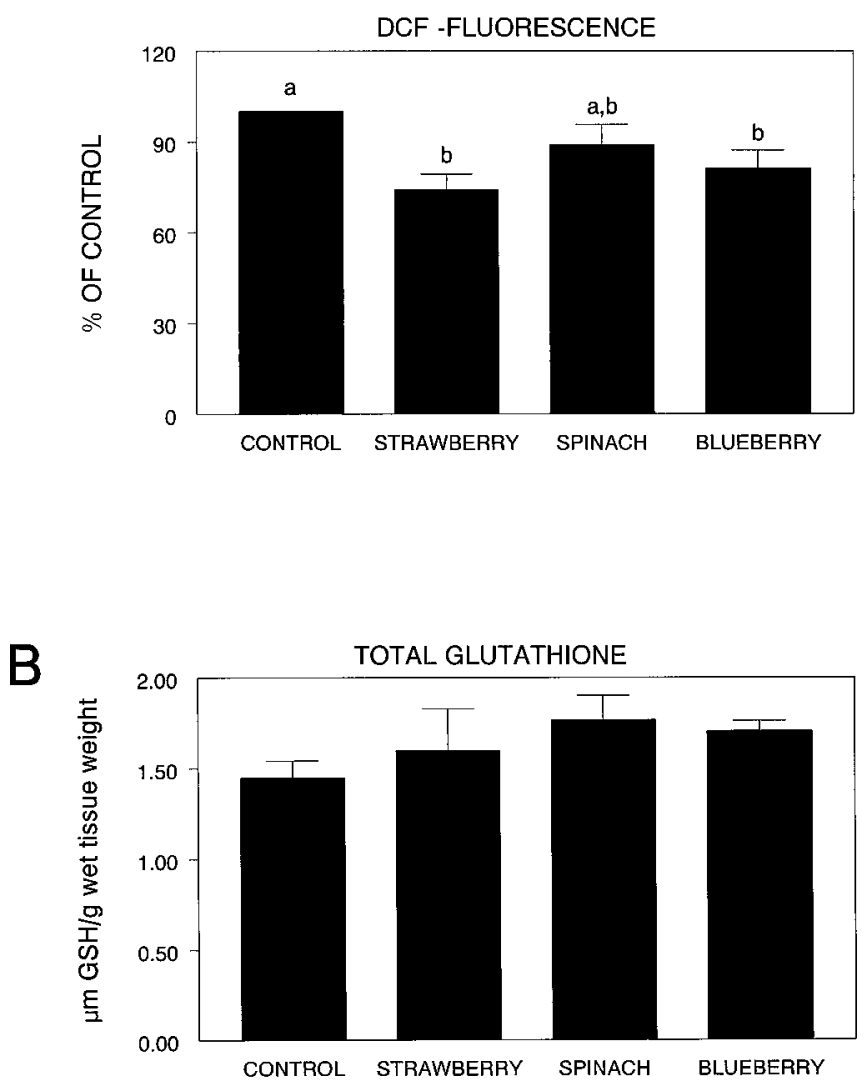

Figure 5. DCF fluorescence in the striata (expressed as percent of control) in the various diet groups $(A)$. Means not sharing a common letter are statistically different from each other $(p<0.05$; Fisher's LSD). $B$ shows total striatal glutathione levels among the four groups.

$p<0.01)$ in the striatum. In this regard, the striata obtained from the spinach-supplemented group did not exhibit any increased level of OS protection relative to the control group $(p>0.05)$. Only the strawberry $(p<0.002)$ and blueberry $(p<0.05)$ groups showed greater native OS protection than controls. Analysis of striatal glutathione (GSH) levels indicated that although dietary supplementation produced increases in GSH that were greater than controls, these differences were not significant $\left(F_{(3,19)}=\right.$ 1.34; $p>0.05$ ) (Fig. 5B).

\section{Vitamin E quantification}

Levels of vitamin E ( $\alpha$-tocopherol and $\gamma$-tocopherol) for only one brain area, the hippocampus, were different between the animals maintained on the control or the various antioxidant diets. Specifically, there was a diet effect for $\alpha$-tocopherol $\left(F_{(3,36)}=2.73\right.$; $p \leq 0.05$ ), with all the antioxidant diets (strawberry, spinach, and blueberry) showing higher levels of vitamin $\mathrm{E}$ than the control $\operatorname{diet}(p<0.05)$, and a diet effect for $\gamma$-tocopherol $\left(F_{(3,36)}=2.65\right.$; $p=0.06)$, with only the strawberry diet $(p<0.05)$ showing higher vitamin E levels than the control diet. There were no differences between the diet groups in vitamin E concentration (either $\alpha$-tocopherol or $\gamma$-tocopherol) in the striatum or cortex $(p>0.05)$.

\section{DISCUSSION}

For many years now studies have shown that there is a highly significant negative association between the intake of total fresh 
fruits and vegetables and ischemic heart disease mortality as reported by Armstrong et al. (1975) in Britain and by Verlangieri et al. (1985) in the United States (see also Hughes, 1995; Mayne, 1996). Consumption of fruits and vegetables is correlated with a reduced incidence and lower mortality rates of cancer in humans (Dell, 1990; Willett, 1994a,b) and animals (Wattenberg and Coccia, 1991). In some cases, even extracts of single foods such as garlic (Pinto et al., 1997) and tomato (lycopene; Sharoni et al., 1997) can have some antitumor properties.

More relevant to brain aging, research has shown that the CNS may show an enhanced vulnerability to OS, since it is deficient in free radical protection and uses $20 \%$ of the total body oxygen (Olanow, 1992), and this vulnerability may increase further in aging (Joseph et al., 1996). These OS increases in vulnerability may be the result of increases in the ratio of oxidized to total glutathione (Olanow, 1992), significant lipofuscin accumulation with bcl-2 increases, increases in membrane lipid peroxidation (Migheli et al., 1994; Yu, 1994), reduced glutamine synthetase (Carney et al., 1994), or alterations in membrane lipids (Denisova et al., 1998).

Several studies have suggested that these increases in OS vulnerability and the resulting behavioral deficits in aging can be reduced through dietary supplementation with ginkgo biloba. For example, memory impairment (Rai et al., 1991), difficulties in concentration (Kleijnen and Knipschild, 1992a,b), and calciuminduced increases in oxidative metabolism (Oyama et al., 1993, 1994) can be reduced by this supplement. It has been shown that it might be possible to reduce the deleterious effects of $\mathrm{AD}$ through dietary supplementation with ginkgo biloba (Kanowski et al., 1996), which has potent antioxidant activity. In addition, recent studies have also suggested that garlic extract can prevent brain atrophy (Moriguchi et al., 1997), as well as learning and memory impairments (Nishiyama et al., 1997) in the senescenceaccelerated mouse.

Moreover, findings from our laboratories have suggested that fruit and vegetable extracts high in both flavonoid levels (spinach and strawberries) as well as total antioxidant activity, as assessed via the ORAC assay (Cao et al., 1995, 1996; Wang et al., 1996), prevented the onset of the deleterious effects of aging on both neuronal and cognitive behavioral functions (Joseph et al., 1998).

However, as far as we can determine, this is the first study that has shown that dietary supplementation with fruit or vegetable extracts that are high in phytonutrient antioxidants can actually reverse some of the age-related neuronal/behavioral dysf unctions that had been shown previously (Joseph et al., 1998; Shukitt-Hale et al., 1998b) to exhibit decrements by 15 months of age. With respect to the functional neuronal indices, the blueberrysupplemented animals showed the greatest increases in carbachol-stimulated GTPase activity, oxotremorine-enhanced $\mathrm{K}^{+}$-ERDA, and ${ }^{45} \mathrm{Ca}^{2+}$-recovery. Thus, it appears that blueberry supplementation may be effective in reversing the deleterious effects of aging on calcium homeostasis that have been reported previously (Landfield and Eldridge, 1994).

The spinach- and strawberry-supplemented groups were less effective in reversing age deficits in these parameters. Spinach and strawberry supplementation primarily increased striatal muscarinic receptor sensitivity, and this appeared to be reflected in the reversal of cognitive behavioral deficits, where all of the diets, including the blueberry-supplemented diet, decreased the latency to find the platform and distance to the platform. In this regard there are numerous papers that suggest that the striatum is involved in mediating cognitive performance (Graybiel, 1998;
Shear et al., 1998; Tanila et al., 1998). It could be suggested then, that dietary enhancement of striatal muscarinic receptor sensitivity in the striatum ultimately may be expressed as improved cognitive performance.

However, it also appears that strawberry supplementation was not effective with respect to GTPase activity, spinach supplementation was only minimally effective, and neither showed any efficacy in altering striatal ${ }^{45} \mathrm{Ca}^{2+}$ recovery. As pointed out above, blueberry supplementation showed significantly greater effects than the other supplemented groups. Therefore, with respect to motor behavior, it may be that greater efficacy is needed on a variety of parameters to see significant reversals in motor behavior. The blueberry-supplemented animals were the only group to show reversals in motor behavioral deficits. It is well known that age-related decrements in motor behavior involving alterations in balance and coordination as reflected in the tests we have used in this experiment have been very resistant to reversal.

In previous studies in which the effects of fruit and vegetable diets have been examined in assessments of cancer or cardiovascular disease, the delineation of the relevant phytochemicals present in these foods, their particular classes, and most effective sites of action has been difficult. One important class that has been recognized is the flavonoids. The flavonoids include, among others: allium compounds (diallyl sulfide, allyl methyl trisulfide) and carotenoids ( $\alpha$-carotene, $\beta$-carotene, lutein, lycopene). They make up an important part of a human diet high in fruits and vegetables (Kuhnau, 1976), with daily flavonoid intake estimated to be as high as $1 \mathrm{gm} / \mathrm{d}$. However, even among the flavonoids it has been difficult to determine which are the most effective, because indices such as antioxidant activity can vary greatly ( $\mathrm{CaO}$ et al., 1997). It may be that it is the interactions of the flavonoids and other phytochemicals present in these fruits and vegetables that is responsible for their beneficial effects. There may also be differences among the various phytonutrients contained in these diets with respect to their brain localization. These are being investigated.

In addition, the phytochemicals contained in spinach, strawberries, and blueberries may produce effects other than antioxidant protection. It is known, for example, that flavonoids can increase membrane fluidity (Ramassamy et al., 1993; Stoll et al., 1996; Halder and Bhaduri, 1998), and a previous experiment has shown (Joseph et al., 1995) that experimental decreases in membrane rigidity (via $S$-adenosyl-L-methionine) can ameliorate deficits in oxotremorine-enhanced $\mathrm{K}^{+}$-ERDA in striatal slices from old animals. As the data with respect to the striatum clearly show, there were no differences in GSH levels as a function of diet, and DCF fluorescence was only modestly reduced by the diets. These changes did not reflect the dramatic reversals in both motor behavioral and neuronal function observed in these experiments. Therefore, the reversals seen in these experiments could have been the result of flavonoid-induced alterations in membrane biophysical properties. Phytonutrients (e.g., anthocyanins and other flavonoids) contained in the fruits and vegetable used in the present study have also been shown to antagonize arachidonic acid transport (Krischer et al., 1997), suppress the 5-lipoxygenase pathway (Mirzoeva and Calder, 1996), and subsequently reduce inflammatory responses.

Thus, it could be that even though the antioxidant levels as determined by ORAC were similar in the diets, these other properties may act in concert with them to produce these differential effects. Additionally, as can be seen from Figure $5 A$, the striatal DCF values of the various diets differed slightly between 
spinach and the other diets, possibly indicating the actual tissue antioxidant levels were not equivalent. For example, recent data indicate that dietary vitamin $\mathrm{E}$ is not taken up equally in all brain areas (Martin et al., 1999). In fact, the uptake of vitamin E in the striatum is lower than in other brain areas examined. Therefore, there may be differences among the various phytonutrients contained in these diets with respect to their brain localization.

We are currently attempting to investigate these and other mechanistic properties of these fruits and vegetables and their principal phytochemicals. However, the findings from this research suggest that nutritional intervention with fruits and vegetables may play an important role in reversing the deleterious effects of aging on neuronal function and behavior.

\section{REFERENCES}

Armstrong BK, Mann JI, Adelstein AM, Eskin F (1975) Commodity consumption and ischemic heart disease mortality, with special reference to dietary practices. J Chron Dis 28:455-469.

Bartus RT (1990) Drugs to treat age-related neurodegenerative problems. The final frontier of medical science? J Am Geriat Soc 38:680-695.

Brandeis R, Brandys Y, Yehuda S (1989) The use of the Morris water maze in the study of memory and learning. Int J Neurosci 48:29-69.

Cao G, Verden CP, Wu AHB, Wang H, Prior RL (1995) Automated oxygen radical absorbance capacity assay using the COBAS FARA II. Clin Chem 41:1738-1744.

Cao G, Sofic E, Prior RL (1996) Antioxidant capacity of tea and common vegetables. J Agric Food Chem 44:3426-3431.

Cao G, Sofic E, Prior RL (1997) Antioxidant and pro-oxidant behavior of flavonoids: Structure-activity relationships. Free Radic Biol Med 22:749-760.

Carney JM, Smith CD, Carney AM, Butterfield DA (1994) Aging- and oxygen-induced modifications in brain biochemistry and behavior. Ann NY Acad Sci 738:44-53.

Cassel D, Selinger Z (1976) Catecholamine-stimulated GTPase activity in turkey erythrocyte membranes. Biochem Biophys Acta 452:538-551.

Daniels WM, van Rensburg SJ, van Zyl JM, Taljaard JJ (1998) Melatonin prevents $\beta$-amyloid-induced lipid peroxidation. J Pineal Res 24:78-82.

Denisova NA, Erat SA, Kelly JF, Roth GS (1998) Differential effect of aging on cholesterol modulation of carbachol stimulated Low-Km GTPase in striatal synaptosomes. Exp Gerontol 33:249-265.

Dell R (1990) An overview of the epidemiological evidence linking diet and cancer. Proc Nutr Soc 49:119-131.

Egashira T, Takayama F, Yamanaka Y (1996) Effects of bifemelane on muscarinic receptors and choline acetyltransferase in the brains of aged rats following chronic cerebral hypoperfusion induced by permanent occlusion of bilateral carotid arteries. Jpn J Pharmacol 72:57-65.

Finch CE, Cohen DM (1997) Aging, metabolism, and Alzheimer's disease: review and hypotheses. Exp Neurol 143:82-102.

Gould TJ, Bickford P (1997) Age-related deficits in the cerebellar $\beta$ adrenergic signal transduction cascade in Fischer 344 rats. J Pharmacol Exp Ther 281:965-971.

Graybiel AM (1998) The basal ganglia and chunking of action repertoires. Neurobiol Learn Mem 70:119-136.

Halder J, Bhaduri AN (1998) Protective role of black tea against oxidative damage of human red blood cells. Biochem Biophys Res Comm 244:903-907.

Hughes K (1995) Diet and coronary heart disease- a review. Ann Acad Med Singapore 24:224-229.

Ingram DK, Jucker M, Spangler E (1994) Behavioral manifestations of aging. In: Pathobiology of the aging rat, Vol 2 (Mohr U, Cungworth DL, Capen CC, eds), pp 149-170. Washington: ILSI.

Jenner P (1996) Oxidative stress in Parkinson's disease and other neurodegenerative disorders. Pathol Biol 44:57-64.

Joseph JA, Berger RE, Engel BT, Roth GS (1978) Age-related changes in the nigrostriatum: a behavioral and biochemical analysis. J Gerontol 33:643-649.

Joseph JA, Bartus RT, Clody DE, Morgan D, Finch C, Beer B, Sesack S (1983) Psychomotor performance in the senescent rodent: reduction of deficits via striatal dopamine receptor up-regulation. Neurobiol Aging 4:313-319.
Joseph JA, Dalton TK, Hunt WA (1988a) Age-related decrements in the muscarinic enhancement of $\mathrm{K}^{+}$-evoked release of endogenous striatal dopamine: an indicator of altered cholinergic-dopaminergic reciprocal inhibitory control in senescence. Brain Res 454:140-148.

Joseph JA, Dalton TK, Roth GS, Hunt WA (1988b) Alterations in muscarinic control of striatal dopamine autoreceptors in senescence: a deficit at the ligand-muscarinic receptor interface? Brain Res 454:149-155.

Joseph JA, Kowatch MA, Maki T, Roth GS (1990) Selective cross activation/inhibition of second messenger systems and the reduction of age-related deficits in the muscarinic control of dopamine release from perifused rat striata. Brain Res 537:40-48.

Joseph JA, Villalobos-Molina R, Yamagami, K, Roth GS, Kelly J (1995) Age specific alterations in muscarinic stimulation of $\mathrm{K}^{+}$-evoked dopamine release from striatal slices by cholesterol and $S$-adenosyl-Lmethionine. Brain Res 673:185-193.

Joseph JA, Villalobos-Molina R, Denisova N, Erat S, Cutler R, Strain JG (1996) Age differences in sensitivity to $\mathrm{H}_{2} \mathrm{O}_{2}$ - or NO-induced reductions in $\mathrm{K}^{+}$-evoked dopamine release from superfused striatal slices: reversals by PBN or Trolox. Free Radic Biol Med 20:821-830.

Joseph JA, Shukitt-Hale B, Denisova NA, Prior RL, Cao G, Martin A, Taglialatela G, Bickford PC (1998) Long-term dietary strawberry, spinach or vitamin E supplementation retards the onset of age-related neuronal signal-transduction and cognitive behavioral deficits. J Neurosci 18:8047-8055.

Kanowski S, Herrmann WM, Stephan K, Wierich W, Horr R (1996) Proof of efficacy of the ginkgo biloba special extract EGb 761 in outpatients suffering from mild to moderate primary degenerative dementia of the Alzheimer type or multi-infarct dementia. Pharmacopsychiatry 29:47-56.

Kleijnen J, Knipschild P (1992a) Ginkgo biloba. Lancet 340:1136-1139.

Kleijnen J, Knipschild P (1992b) Ginkgo biloba for cerebral insufficiency. Br J Clin Pharmacol 34:352-358.

Kluger A, Gianutsos JG, Golomb J, Ferris S H, George AE, Frannssen E, Reisberg B (1997) Patterns of motor impairment in normal aging, mild cognitive decline, and early Alzheimer's disease. J Gerontol $52: 28-39$

Kornhuber J, Schoppmeyer K, Bendig, C, Riederer P (1996) Characterization of $[3 \mathrm{H}]$ pentazocine binding sites in post-mortem human frontal cortex. J Neural Transm 103:45-53.

Krischer SM, Eisemann M, Bock A, Mueller MJ (1997) Proteinfacilitated export of arachidonic acid from pig neutrophils. J Biol Chem 272:10601-10607.

Kuhnau J (1976) The flavonoids. A class of semi-essential food components: their role in human nutrition. World Rev Nutr Diet 24:117-191.

Landfield PW, Eldridge JC (1994) The glucocorticoid hypothesis of agerelated hippocampal neurodegeneration: role of dysregulated intraneuronal $\mathrm{Ca}^{2+}$. Ann NY Acad Sci 746:308-321.

Lebel CP, Ischiropolos H, Bondy SC (1992) Evaluation of the probe $2^{\prime}, 7^{\prime}$ - dichlorofluorescein as an indicator of reactive oxygen species formation and oxidative stress. Chem Res Toxicol 5:227-231.

Levine MS, Cepeda C (1998) Dopamine modulation of responses mediated by excitatory amino acids in the neostriatum. Adv Pharmacol 42:724-729.

Lowry OH, Rosebrough NJ, Farr AL, Randall RJ (1951) Protein measurement with the folin phenol reagent. J Biol Chem 193:256-275.

Martin A, Janigian D, Shukitt-Hale B, Prior RL, Joseph JA (1999) Vitamin $\mathrm{E}$ intake and levels of vitamins $\mathrm{E}$ and $\mathrm{C}$ in the central nervous system and peripheral tissues: implications for health recommendations. Brain Res, in press.

Martin A, Blumberg J, Foxall T, Meydani M (1997) Vitamin E inhibits low-density lipoprotein-induced adhesion of monocytes to human aortic endothelial cells in vitro. Arterioscler Thromb Vasc Biol $17: 429-436$.

Mayne ST (1996) Beta-carotene, carotenoids and disease prevention in humans. FASEB J 10:690-701.

Migheli A, Cavalla P, Piva R, Giordana MT, Schiffer D (1994) Bcl-2 protein expression in aged brain and neurodegenerative diseases. NeuroReport 5:1906-1908.

Mirzoeva OK, Calder PC (1996) The effect of propolis and its components on eicosanoid production during the inflammatory response. Prostaglandins Leukot Essent Fatty Acids 55:441-449.

Moriguchi T, Saito H, Nishiyama N (1997) Anti-aging effect of aged garlic extract in the inbred brain atrophy mouse model. Clin Exp Pharmacol Physiol 24:235-242. 
Morris R (1984) Developments of a water-maze procedure for studying spatial learning in the rat. J Neurosci Methods 11:47-60.

Nagahara AH, Gill TM, Nicolle M, Gallagher M (1996) Alterations in opiate receptor binding in the hippocampus of aged Long-Evans rats. Brain Res 707:22-30.

Nishiyama N, Moriguchi T, Saito H (1997) Beneficial effects of aged garlic extract on learning and memory impairment in the senescenceaccelerated mouse. Exp Gerontol 32:149-160.

Olanow CW (1992) An introduction to the free radical hypothesis in Parkinson's disease. Ann Neurol 32:S2-S9.

Oyama YA, Hayashi $\mathrm{H}$, Ueha T (1993) $\mathrm{Ca}^{+2}$-induced increase in oxidative metabolism of dissociated mammalian brain neurons: effect of extract of Ginkgo Biloba leaves. Jpn J Pharmacol 61:367-370.

Oyama Y, Fuchs PA, Katayama N, Noda K (1994) Myricetin and quercetin, the flavonoid constituents of Ginkgo biloba extract, greatly reduce oxidative metabolism in both resting and $\mathrm{Ca}^{+2}$-loaded brain neurons. Brain Res 635:125-129.

Pike CJ, Ramezan-Arab N, Cotman CW (1997) $\beta$-amyloid neurotoxicity in vitro: evidence of oxidative stress but not protection by antioxidants. J Neurochem 69:1601-1611.

Pinto JT, Qiao C, Xing J, Rivilin RS, Protomastro MLW, Weissler ML, Tao Y, Thaler H, Heston WD (1997) The effects of garlic thioallyl derivatives on growth glutathione concentration and polyamine formation of human prostate carcinoma cells in culture. Am J Clin Nutr 66:398-405.

Prior RL, Cao G, Martin A, Sofic E, McEwen J, O’Brien C, Lischner N, Ehlenfeldt M, Kalt W, Krewer G, Mainland M (1998) Antioxidant capacity as influenced by total phenolic and anthocyanin content, maturity and variety of Vaccinium species. J Agric Food Chem 46:2586-2593.

Rai SS, Shovlin C, Wesnes KA (1991) A double-blind placebo controlled study of Ginkgo biloba extract ("tanakan") in elderly outpatients with mild to moderate memory impairment. Curr Med Res Opin 12:350-355.

Ramassamy C, Girbe F, Christen Y, Costentin J (1993) Ginkgo biloba extract EGb 761 or Trolox vitamin $\mathrm{C}$ prevent the ascorbic acid/ $/ \mathrm{Fe}^{2+}$ induced decrease in synaptosomal membrane fluidity. Free Radic Res Commun 19:341-350.

Rapp PR, Rosenberg RA, Gallagher M (1987) An evaluation of spatial information processing in aged rats. Behav Neurosci 101:3-12.

Sayre LM, Zelasko DA, Harris PL, Perry G, Salomon R G, Smith MA (1997) 4-Hydroxynonenal-derived advanced lipid peroxidation end products are increased in Alzheimer's Disease. J Neurochem 68:2092-2097.

Sharoni Y, Giron E, Rise M, Levy J (1997) Effects of lycopene-enriched tomato oleoresin on 7,12-dimethyl-benz[a]anthracene-induced rat mammary tumors. Cancer Detect Prevent 21:118-123.

Shear DA, Dong J, Haik-Creguer KL, Bazzett TJ, Albin RL, Dunbar GL (1998) Chronic administration of quinolinic acid in the rat striatum causes spatial learning deficits in a radial arm water maze. Exp Neurol 150:305-311.
Shukitt-Hale B, Erat SA, Joseph JA (1998a) Spatial learning and memory deficits induced by dopamine administration with decreased glutathione. Free Radic Biol Med 24:1149-1158.

Shukitt-Hale B, Mouzakis G, Joseph J A (1998b) Psychomotor and spatial memory performance in aging male Fischer 344 rats. Exp Gerontol 33:615-624.

Smith CD, Carney JM, Starke-Reed PE, Oliver CN, Stadtman ER, Floyd RA, Markesbery WR (1991) Excess brain protein oxidation and enzyme dysfunction in normal aging and in Alzheimer's disease. Proc Natl Acad Sci USA 88:10540-10543.

Smith MA, Udnicka-Nawrot M, Richey PL, Praprotnik D, Mulvihill P, Miller CA, Sayre, LM, Perry G (1995) Carbonyl-related posttranslational modification of neurofilament protein in the neurofibrillary pathology of Alzheimer's disease. J Neurochem 64:2660-2666.

Smith MA, Perry G, Richey PL, Sayre LM, Anderson VE, Beal MF, Kowall N (1996) Oxidative damage in Alzheimer's. Nature 382:120-121.

Stoll S, Scheur K, Pohl O, Muller WE (1996) Ginkgo biloba extract Egb761 independently improves changes in passive avoidance learning and brain membrane fluidity in the aging mouse. Pharmacopsychiatry 29:144-149.

Tanila H, Bjorklund M, Riekkinen Jr P (1998) Cognitive changes in mice following moderate MPTP exposure. Brain Res Bull 45:577-582.

Ueda K, Shinohara S, Yagami T, Asakura K, Kawasaki K (1997) Amyloid $\beta$ protein potentiates $\mathrm{Ca}^{2+}$ influx through L-type voltage-sensitive $\mathrm{Ca}^{2+}$ channels: a possible involvement of free radicals. J Neurochem 68:265-271.

Van der Staay FJ, de Jonge M (1993) Effects of age on water escape behavior and on repeated acquisition in rats. Behav Neural Biol 60:33-41.

Verlangieri AJ, Kapeghian JC, el-Dean S, Bush M (1985) Fruit and vegetable consumption and cardiovascular mortality. Medical Hypothesis 16:7-15.

Wang H, Cao G, Prior R (1996) Total antioxidant capacity of fruits. J Agric Food Chem 44:701-705.

Wattenberg LW, Coccia JB (1991) Inhibition of 4-(methylnitrosamino)1-(3-pyridyl)-1-butanone carcinogenesis in mice by D-limonene and citrus fruit oils. Carcinogenesis 12:115-117.

Willett CW (1994a) Diet and health: what should we eat? Science 264:532-537.

Willett CW (1994b) Micronutrients and cancer risk. Am J Clin Nutr 59:162S-165S

Yamagami K, Joseph JA, Roth GS (1992) Decrement in muscarinicreceptor stimulated low KM GTPase in striata and hippocampus from aged rat. Brain Res 57:327-331.

Yu BP (1994) Cellular defenses against damage from reactive oxygen species. Physiol Rev 76:139-162.

Yufu F, Egashira T, Ymanaka Y (1994) Age-related changes of cholinergic markers in the rat brain. Jpn J Pharmacol 66:247-255. 